\title{
Penerapan Edukasi Gizi Buruk Pada Generasi Alfa Sebagai Penerus Generasi Milenial di Tanjung Priok Jakarta
}

\author{
Liza Agustina Maureen Nelloh ${ }^{1 *}$, Mahonri Lukas², \\ Prima Dyah Indira ${ }^{3}$, Rio kurniawan ${ }^{4}$, Rismatio ${ }^{5}$ \\ ${ }^{12345}$ Sekolah Tinggi Manajemen Ipmi, Jakarta, Indonesia 12750 \\ Author E-mail: liza.nelloh@ipmi.ac.id
}

\section{A B S T R A K}

Generasi Milenial memberikan sumbangsih yang cukup signifikan pada ekonomi Indonesia. Generasi ini memiliki penerus yaitu generasi Alfa yang akan mewarisi dan meneruskan kesuksesan generasi Milenial. Akan tetapi berdasarkan data resmi pemerintah Indonesia, terbukti bahwa masih banyak anak generasi Alfa yang mengalami kekurangan gizi dan stunting khususnya di Tanjung Priok, Jakarta Utara. Hal ini disinyalir karena kurangnya edukasi terhadap generasi milenial itu sendiri mengenai dampak gizi buruk bagi perkembangan anak. Oleh karena itu, kegiatan Pengabdian Masyarakat ini dilakukan untuk memberikan edukasi bagi orang tua generasi Alfa yang kebanyakan berasal dari generasi milenial. Kegiatan sosial ini dilaksanakan pada di Gereja St. Fransiskus Xaferius, Tanjung Priok, Jakarta Utara. Kegiatan ini diadakan agar para orang tua bisa semakin peduli kepada pola hidup yang sehat untuk melakukan pencegahan terhadap masalah gizi buruk di Indonesia. Kegiatan ini bermanfaat untuk untuk meningkatkan pengetahuan dan kesadaran tentang penting menjaga pola hidup yang baik kepada orang tua anak asuh ASAK( Ayo Sekolah Ayo Kuliah).

Kata Kunci: Gizi Buruk, Generasi Alfa, Kegiatan Sosial.

\section{A B S T R A C T}

Millennial generation contributes significantly to the Indonesian economy. This generation has successors who are called the Alfa generations who will inherit and succeed in reaching the Millennial generation. However, based on official Indonesian government data, it is proven that there are still many Alfa Generation children who are malnourished and have special stunting in Tanjung Priok, North Jakarta. This is allegedly due to lack of education of the millennial generation itself regarding malnutrition for children's development. Therefore, this Community Service activity is carried out to provide education for the older generation of Alfa which is mostly obtained from millennial generation. This social activity is carried out in the Church of St. Fransiskus Xaferius, Tanjung Priok, North Jakarta. This activity is conducted to educate their parents to be more concern about healthy lifestyles to update nutrition issues in Indonesia. This activity is useful to increase knowledge and awareness about the importance of a good lifestyle for ASAK (Ayo Sekolah Ayo Kuliah).

Key word: Malnourished, Alpha Generation, Social Activity. 
Copyright (C) 2020 Authors. This is an open access article distributed under the Creative Commons Attribution License, which permits unrestricted use, distribution, and reproduction in any medium, provided the original work is properly cited.

\section{PENDAHULUAN}

Saat ini di Indonesia, generasi Milenial memberikan sumbangsih yang cukup signifikan pada ekonomi Indonesia. Generasi milenial lahir pada tahun 1980-2000 yang pada saat ini menunjukkan beberapa sumbangsih antara lain kreatifitas dan sikap proaktif, modal psikologis, dan dukungan organisasi (Archianti, 2017). Beberapa sumber lain juga menyebutkan sumbangsih generasi milenial pada dunia kewirausahaan Indonesia, antara lain dengan munculnya Go-Jek dan Tokopedia yang dipimpin oleh Nadiem Makariem dan William Tanuwijaya. Kedua pemilik perusahaan Unicorn di Indonesia tersebut adalah generasi Milenial. Seperti yang diketahui bersama, baik Go-Jek maupun Tokopedia memberikan sumbangsih yang sangat besar pada ekonomi Indonesia. Akan tetapi, seperti generasigenerasi sebelumnya, generasi milenial saat ini melahirkan sebuah generasi pengganti yaitu generasi Alfa. Generasi Alfa lahir pada tahun 2010-sampai saat ini yang sangat banyak dipengaruhi oleh Revolusi Industri 4.0 (Panuntun, dkk, 2019).

Selain kemajuan teknologi pada generasi Alfa, pemerintah Indonesia melalui program Sustainable Development Goals (SDG's) berkomitmen untuk mencapai pembangunan anak di Indonesia (PPPA, 2019). Beberapa target tersebut antara lain "kemiskinan anak; tidak ada lagi anak-anak kekurangan gizi dan meninggal karena penyakit yang bisa diobati; menciptakan lingkungan yang ramah terhadap anak; memenuhi kebutuhan pendidikan anak khususnya pendidikan di usia dini; dan target lainnya."

Dengan kata lain, generasi Alfa harus diberikan kesejahteraan yang maksimal dari pemerintah sebagai pengganti generasi sebelumnya agar diharapkan generasi ini dapat memberikan sumbangsih yang maksimal khususnya di bidang kewirausahaan dan ekonomi seperti pada generasi orang tuanya yaitu generasi milenial. Berdasarkan data Kementrian Pemberdayaan Perempuan dan Perlindungan Anak (PPPA) dan Badan Pusat Statistik Indonesia, di tahun 2019, jumlah anak usia 0-17 berjumlah sekitar 75 juta jiwa dari total populasi Indonesia yaitu 260 juta jiwa. Dari data tersebut dapat dilihat melalui Gambar 1. Jumlah proporsi anak terbanyak yaitu usia 7-12 tahun yaitu $33.4 \%$ dan anak usia 0-5 tahun berkisar $27.6 \%$ dari total jumlah anak di Indonesia. Hal ini berarti 1 dari 3 penduduk Indonesia adalah anak-anak.

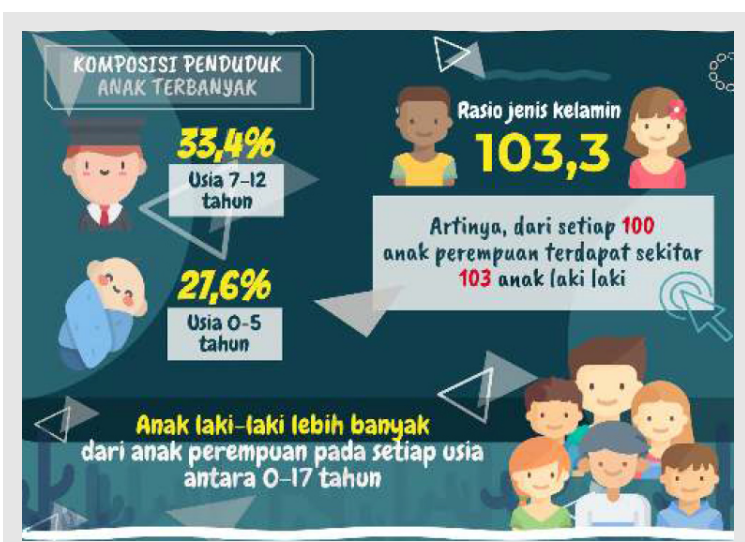

Gambar 1. Komposisi Jumlah Anak di Indonesia Sumber: Proyeksi SUPAS Nasional (2015)

Selanjutnya berdasarkan data proyeksi SUPAS Nasional (2015) tersebut disebutkan bahwa dari tahun 2018 sampai 2025, terdapat penurunan dan staganansi jumlah anak pada klasifikasi usia 0-17 terutama pada klasifikasi generasi Alfa. Hal tersebut dapat dilihat pada Tabel 1 dibawah ini. Hal ini membuktikan bahwa jumlah anak generasi Alfa sebagai penerus bangsa Indonesia menjadi sangat penting untuk diperhatikan dari segala sisi terutama gizi dan kesehatan.

Akan tetapi, berdasarkan Riset Kesehatan Dasar (Riskesdas) pada tahun 2018, anak balita atau generasi Alfa mengalami stunting sebesar 30,8\%. Dari jumlah tersebut, balita golongan yang sangat pendek $11,5 \%$, dan 19,3\% merupakan balita yang pendek. Kemudian data PPPA mengenai Profil 
Tabel 1. Proyeksi Klasifikasi Usia di Indonesia

\begin{tabular}{ccccccccc}
\hline Klasifikasi Usia & $\mathbf{2 0 1 8}$ & $\mathbf{2 0 1 9}$ & $\mathbf{2 0 2 0}$ & $\mathbf{2 0 2 1}$ & $\mathbf{2 0 2 2}$ & $\mathbf{2 0 2 3}$ & $\mathbf{2 0 2 4}$ & $\mathbf{2 0 2 5}$ \\
\hline 0-4 (Generasi Alfa) & 21990 & 21974 & 21952 & 21892 & 21856 & 21845 & 21858 & 21896 \\
\hline $5-9$ & 22044 & 21999 & 21945 & 21939 & 21939 & 21940 & 21927 & 21906 \\
\hline $0-17$ & 79552 & 79472 & 79373 & 79275 & 79184 & 79100 & 79038 & 78976 \\
\hline
\end{tabular}

Sumber: Proyeksi SUPAS Nasional (2015)

Akan tetapi, berdasarkan Riset Kesehatan Dasar (Riskesdas) pada tahun 2018, anak balita atau generasi Alfa mengalami stunting sebesar 30,8\%. Dari jumlah tersebut, balita golongan yang sangat pendek 11,5\%, dan 19,3\% merupakan balita yang pendek. Kemudian data PPPA mengenai Profil Anak (2019) menunjukkan bahwa indikator kesehatan pada anak pada golongan usia generasi Alfa masih terdapat beberapa gangguan kesehatan. Kemudian riset tersebut juga menunjukkan bahwa $17.7 \%$ generasi Alfa masih mengalami gizi kurang bahkan gizi buruk.

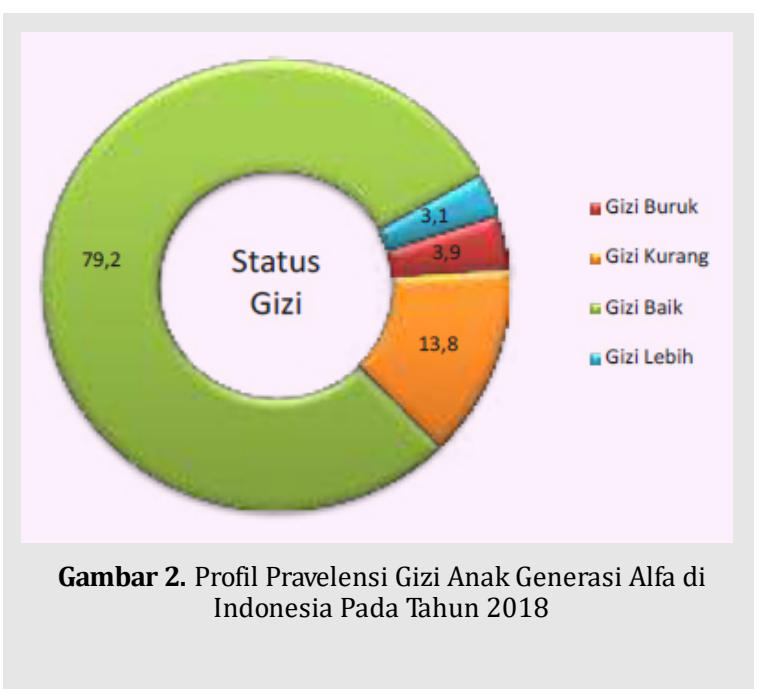

Sebagai generasi pengganti generasi Milenial asupan gizi yang baik sangat penting agar memberikan kesejahteraan pada generasi Alfa di Indonesia. Akan tetapi dengan masih adanya $17,7 \%$ yang belum mendapatkan gizi yang baik, maka pengabdian masyarakat ini dilakukan. Tanjung Priok merupakan salah satu daerah di DKI Jakarta (Jakarta Utara) yang mengalami gizi buruk pada anak generasi Alfa. Berdasarkan data tersebut disebutkan bahwa orang tua penderita gizi buruk tidak mengetahui bahwa anaknya mengalami gizi buruk. Kemudian, beberapa tim mengalami observasi di salah satu daerah Tanjung Priok yaitu di Gereja Paroki St. Fransiskus Xaferius,
Tanjung Priok. Hasil observasi menunjukkan bahwa masih terdapat orang tua yang belum terlalu paham mengenai pentingnya gizi bagi anak-anaknya. Beberapa orang tua tersebut antara lain berasal dari golongan ibu rumah tangga, supir dan tukang cuci dan gosok rumahan. Beberapa golongan ini juga memiliki usaha kecil di Tanjung Priok, sehingga diharapkan dengan pengetahuan gizi yang baik bagi anaknya dapat mempersiapkan generasi yang lebih baik untuk meneruskan usaha orang tuanya yaitu generasi Milenial di Tanjung Priok.

Berdasarkan data Dinas Kesehatan dan Biro Kesejahteraan Sosial Provinsi DKI Jakarta pada tahun 2015-2019, jumlah gizi buruk tertinggi terdapat di Jakarta Utara yaitu sebanyak 882 kasus (lihat Gambar 3). Berdasarkan data gizi buruk di Jakarta Utara dan Tanjung Priok, maka Tujuan dari pengabdian masyarakat ini antara lain memberikan wawasan tentang betapa pentingnya kecukupan gizi untuk anak anak di usia sekolah dasar, dan membantu pemerintah dalam mengurangi masalah gizi buruk di Indonesia, khususnya di Tanjung Priok Jakarta Utara yang masih mengalami gizi buruk. Selain itu, kegiatan ini bertujuan untuk mengajak semua golongan termasuk generasi Milenial dan Zilenial (generasi Z) untuk berpartisipasi aktif mengurangi jumlah gizi buruk pada anak generasi Alfa di Jakarta Indonesia. Profil peserta orang tua dari anak asuh program ASAK (Ayo Sekolah Ayo Kuliah), yang duduk dibangku sekolah dasar, dihadiri sekitar 50 orang tua, dimana profile dari profesi dari orang tua anak anak tersebut adalah sebagai buruh, pembantu rumah tangga yang diyakini memiliki beberapa usaha kecil di Tanjung Priok, Jakarta Utara.

Kemudian, manfaat dari kegiatan Pengabdian Masyarakat ini adalah dapat membantu 


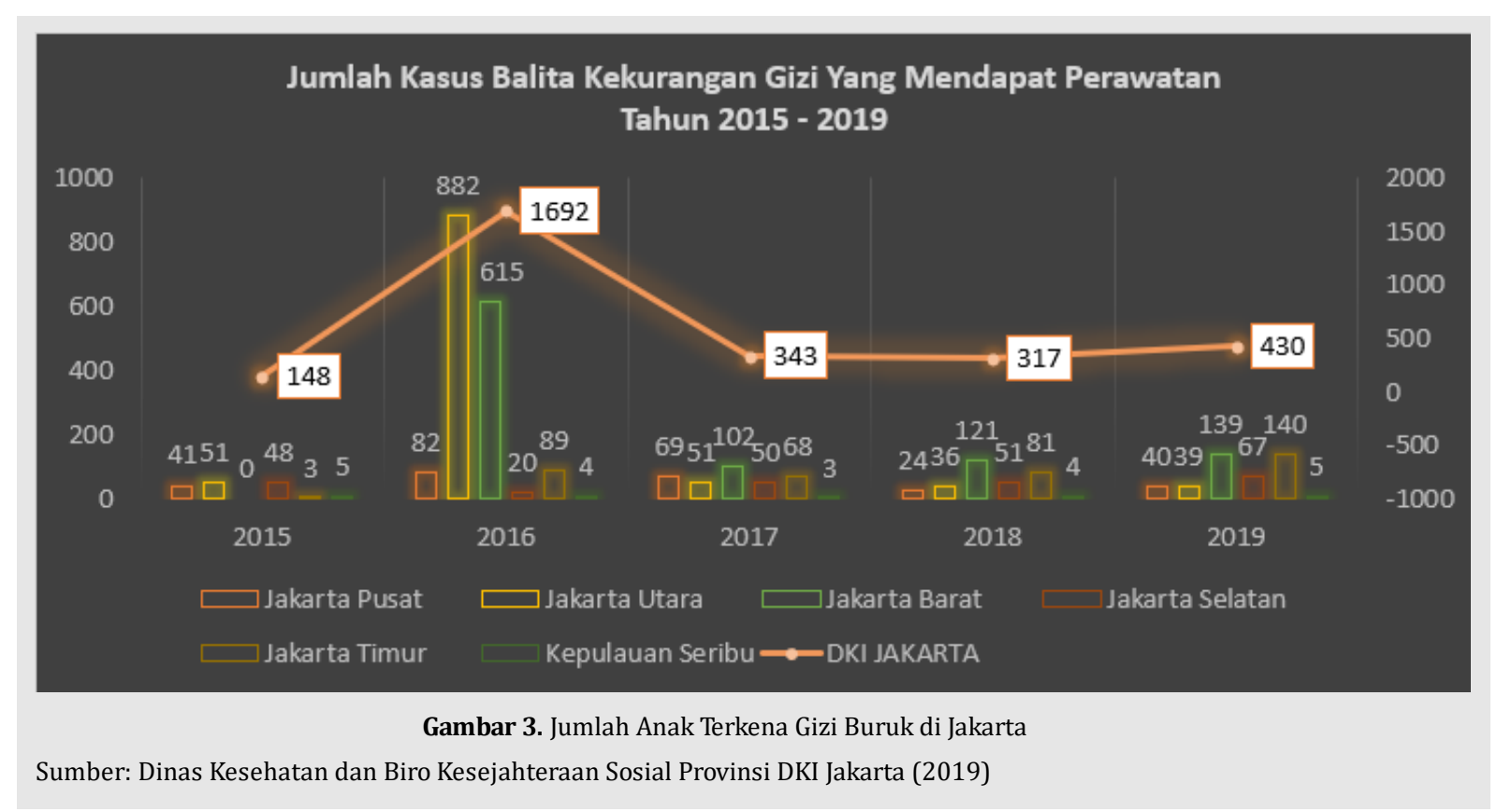

pemerintah mengurangi masalah gizi buruk bagi anak generasi Alfa yaitu berasal dari gaya hidup orang tua dan kurangnya nutrisi pada anak generasi Alfa. Selain itu, dengan partisipasi generasi Milenial dan Zilenial akan membantu mengurangi jumlah anak generasi Alfa yang bergizi buruk sebagai penerus generasi-generasi sebelumnya.

\section{METODE PELAKSANAAN}

Metode pelaksaaan dari kegiatan ini adalah seminar edukasi mengenai gizi buruk yang dilaksanakan pada bulan Januari 2020. Salah satu dukungan kami dalam rangka mengurangi gizi buruk terutama di Indonesia adalah memberikan seminar edukasi gizi baik kepada orang tua dari komunitas Ayo sekolah Ayo Kuliah di Gereja Katholik St. Fransiskus Xaferius, Tanjung Priok. Metode kegiatan pengembangan komunitas sosial yang diterapkan adalah sebagai berikut:

a. Presentasi tentang gizi baik oleh Dr.Angel.

b. Membuka sesi tanya jawab.

c. Pembagian sembako.

d. Acara makan bersama.

\section{RESULT AND DISCUSSION}

Secara garis-besar dari kegiatan kepedulian sosial ini sebagai berikut: penyusuan ide kegiatan sosial, pemilihan sasaran/tujuan aktivitas sosial ini, penentuan waktu, tempat dan lokasi, persiapan kegiatan,dan akhirnya penyusunan laporan hasil kegiatan. Adapun rincian biaya adalah sebagai berikut:

Tabel 2. Biaya Pelaksanaan

\begin{tabular}{ll}
\hline \multicolumn{1}{c}{ Uraian } & \multicolumn{1}{c}{ Total Biaya } \\
\hline Konsumsi (nasi box) & Rp. 2,400,000 \\
\hline Paket Sembako : & \\
Minyak & Rp. $1,038,400$ \\
Beras @5kg & Rp. 2,745,600 \\
Energen & Rp. 617,155 \\
Tanggo & Rp. 229,878 \\
Teh Celup & Rp. 226,670 \\
Minyak & Rp. 22,300 \\
Energen \& Teh Celup & Rp. 85,000 \\
plastik oval polos & Rp. 25,000 \\
Plastik & Rp. 15,000 \\
Loco Merah & Rp. 43,500 \\
Print Kupon & Rp. $123,812.50$ \\
Banner & Rp. 76,000 \\
Total & $\mathbf{7 , 6 4 8 , 3 1 5 . 5 0}$ \\
\hline
\end{tabular}

Kegiatan sosial ini dilaksanakan pada tanggal 12 Januari 2020 di Gereja St. Fransiskus Xaferius, Tanjung Priok, Jakarta Utara. Kegiatan ini diadakan agar para orang tua bisa semakin peduli kepada pola hidup yang sehat untuk melakukan pencegahan terhadap masalah gizi 
buruk di Indonesia. Hal ini dikarenakan setiap perubahan akan bermulai dari keluarga dan akan memberikan dampak besar bagi Indonesia.

\section{KESIMPULAN}

Kegiatan ini telah mengoptimalkan kegiatan social untuk memberikan manfaat melalui pelatihan untuk meningkatkan pengetahuan dan kesadaran tentang penting menjaga pola hidup yang baik kepada orang tua anak asuh ASAK (Ayo Sekolah Ayo Kuliah). Acara berlangsung pada hari Minggu tanggal 12 Januari 2020 di Gereja St Fransiskus Xaferius, Tanjung Priok dan melibatkan 50 orang tua. Seminar ini melibatkan Dr. Angel yang bekerja di Kalbe Farma, sebagai narasumber, di akhir acara kami juga membagikan paketan sembako sebagai contoh dari makanan yang sehat.

\section{DAFTAR PUSTAKA}

Archianti, P. (2017). Memprediksi Kreativitas Generasi Millenial di Tempat Kerja. Jurnal Ilmiah Penelitian Psikologi: Kajian Empiris \& Non-Empiris, 3(2), 61-68.

Panuntun, D. F., Tanduklangi, R., Adeng, M., \& Randalele, C. E. (2019). Model Ibadah Sekolah Minggu KreatifInteraktif Bagi Generasi Alfa Di Gereja Toraja. BIA': Jurnal Teologi dan Pendidikan Kristen Kontekstual, 2(2), 193-208.

Sihombing, R. A. (2018). Selain Asmat, Gizi Buruk Juga Terjadi di Tanjung Priok: https:// www.liputan6.com/news/read/3255436/selain-asmat-gizi-buruk-juga-terjadi-di-tanjung-priok Diunduh tanggal 5 Januari 2020.

LAMPIRAN 1

SUSUNAN PERSONALIA

\begin{tabular}{lllll}
\hline No & Nama & Jabatan & Bidang Keahlian & Instansi ASAL \\
\hline 1 & Ibu Liza Agutina Maureen Nelloh & Pembimbing & Manajemen & IPMI \\
\hline 2 & Mahori Lukas & Anggota & Manajemen & IPMI \\
\hline 3 & Prisma D Indira & Anggota & Manajemen & IPMI \\
\hline 4 & Rio Kurniawan & Anggota & Manajemen & IPMI \\
\hline 5 & Rismatio & Anggota & Manajemen & IPMI \\
\hline
\end{tabular}

